\title{
0352 DRIVING ERRORS INFLUENCE AN OLDER DRIVERS DECISION TO GIVE UP OR RESTRICT DRIVING
}

L Keay*, B Munoz, K Turano, C Munro, D D Duncan, K Baldwin, K J Bandeen-Roche, E W Gower, S K West Correspondence: The George Institute for International Health, Level 7, 341 George Street, Sydney 2000, Australia

10.1136/ip.2010.029215.352

Purpose Explore driving errors in older drivers and the subsequent decision to restrict or stop driving.

Methods 1425 drivers aged 67-87, enrolled in a longitudinal study completed 5-day naturalistic driving assessment. Rate of failure to stop at red traffic lights, stop signs or safely execute left turns were modelled as predictors of stopping or restricting driving.

Results 1237 (87\%) completed 12-months, excluding those already restricting driving( $\mathrm{n}=35), 1.5 \%(18 / 1202)$ had stopped and $3.4 \%(41 / 1202)$ restricted their driving. Errors were observed in $32 / 1171$ (2.7\%) participants at red lights, 75/1155 $(6.5 \%)$ at stop-signs, $88 / 1170(7.5 \%)$ at left turns. The average failure rate per traffic light, stop sign and left turn was $0.2 \%$, $2.2 \%$ and $0.4 \%$, respectively. Police stopped 182 drivers during the year (15\%), 81 were issued infringement notices $(7 \%)$ and 34 were advised to stop or restrict driving (3\%) however these factors were not predictive of incident driving change. Those with traffic light failures were more likely to stop or restrict their driving (adjusted OR 1.295; 95\% CI 1.078 to 1.555 per per cent increase in failure rate). Failed stop sign $(p=0.6)$ and left turns $(p=0.4)$ were not predictive.

Conclusions Driving errors were measured objectively in a large cohort of older drivers. While a rare event, red traffic light errors increased likelihood of subsequently restricting or ceasing driving. These findings lend support for self-regulation of driving exposure. 